\title{
Spectroscopic Characterization of Urea Aqueous Solutions: Experimental Phase Diagram of the Urea-Water Binary System
}

\author{
Ivana Durickovic, ${ }^{\mathrm{a}}$ Laura Thiébaud, ${ }^{\mathrm{b}}$ Patrice Bourson, ${ }^{\mathrm{b}}$ Thomas Kauffmann, ${ }^{\mathrm{b}}$ Mario \\ Marchetti $^{\mathrm{a}}$
}

aLaboratoire Régional des Ponts et Chaussées de Nancy, Centre d’Études Techniques de l'Équipement de l’Est, 71 rue de la Grande Haie, 54510 Tomblaine, France

${ }^{b}$ Laboratoire Matériaux Optiques, Photonique et Systèmes, University Paul Verlaine of Metz and Supélec, 2 rue Edouard Belin, 57070 Metz, France

\begin{abstract}
Raman spectroscopy was used to analyze mixtures of urea and water in order to identify the influence of the urea concentration on the solution's freezing point. Our approach consisted in the analysis of urea aqueous solutions and the determination of their phase transitions at low temperatures. Hence, Raman spectra of these solutions were acquired in a -30 to $10^{\circ} \mathrm{C}$ temperature range. This enabled us to build the experimental phase diagram of the urea-water binary system.
\end{abstract}

Index Headings: Urea water solutions; Phase transitions; Raman spectroscopy; Phase diagram.

\section{INTRODUCTION}

Discovered in 1773, urea, $\mathrm{CO}\left(\mathrm{NH}_{2}\right)_{2}$, was the first organic compound synthesized in a laboratory from inorganic materials by Wohler in 1828. 1 Its synthesis came from the reaction between carbon dioxide and ammonia at high temperature and high pressure. ${ }^{2}$ Nowadays, the reverse reaction of decomposition of urea into ammonia and carbon dioxide is widely used in vehicular applications. In this specific case, its use decreases the release into the atmosphere of some chemical species present in the vehicles exhaust gases. ${ }^{3,4}$ It is especially considered to be very effective for the decrease of the $\mathrm{NO}_{\mathrm{x}}$ emissions from diesel engines and heavy-duty vehicles. ${ }^{5,6}$ Indeed, the ammonia, formed by the decomposition of urea injected in the catalytic exhaust systems, can react with $\mathrm{NO}_{\mathrm{x}}$ emissions to form harmless $\mathrm{N}_{2}$ and $\mathrm{H}_{2} \mathrm{O}$. An optimization of the injected amounts of urea is necessary in order to avoid any ammonia emission. ${ }^{7}$

In some countries, urea is also used in winter maintenance as a pavement or airport runway deicing product. Indeed, during winter, chemicals having the property to lower the freezing point are applied on pavements in order to prevent or break the ice-pavement bond. ${ }^{8,9}$ However, these products often have negative environmental impacts. As an example, it was shown that the presence of urea in the environment can induce the eutrophication of lakes ${ }^{10}$ and diminish the diversity of the fauna. ${ }^{11}$ In order to diminish urea's environmental impacts, as well as the cost of its use in winter maintenance, an optimization of the quantities applied is necessary. It is therefore essential to know the concentration of the urea aqueous solution that has the appropriate "protection temperature" corresponding to its freezing point.

In this work, the concentration influence on the Raman spectrum was identified by the analysis of several urea aqueous solutions at room temperature. In addition to urea-characteristic peaks, the urea-induced modification can be observed in the $2900-3700 \mathrm{~cm}^{-1}$ spectral range. This zone is of particular interest as it contains the urea's $\mathrm{NH}_{2}$ stretching vibrations, but also the water's $\mathrm{O}-\mathrm{H}$ stretching vibrations. Furthermore, the $\mathrm{O}-\mathrm{H}$ vibrations reflect the hydrogen-bonding network ${ }^{12}$ and are thus sensitive to the presence of dissolved salts in water, but also at temperature.

For the freezing point monitoring, which is necessary in the winter maintenance context, the phase diagram of the urea-water binary system was experimentally elaborated. The conventional techniques for the phase transition determination are based on the monitoring of heat, volume, or 
pressure occurring during the phase transition. In this paper, an alternative method based on Raman spectroscopy is proposed, and the urea-water phase diagram is constructed by Raman probing and analyzing in the cooling process of the solution. The temperature range chosen for this study corresponds to the one that can be encountered during the winter season.

\section{EXPERIMENTAL}

Measurements on urea aqueous solutions were made with a Horiba-Jobin Yvon HE Raman spectrometer. The spectrometer used a $532 \mathrm{~nm}$ laser with a $300 \mathrm{~mW}$ maximum output power and a 920 lines/millimeter grating with a $3 \mathrm{~cm}^{-1}$ spectral resolution, covering the $950-3870 \mathrm{~cm}^{-1}$ spectral range. The laser beam was focused on the surface sample with a $50 \times$ long-working distance objective. The Raman signal was collected by a CCD camera of 1024 pixels.

The objective was located at $8 \mathrm{~mm}$ from the sample surface. Its focal distance being $10.6 \mathrm{~mm}$, the investigated volume (with a depth of field of 20-30 $\mu \mathrm{m}$ ) was thus located underneath the liquid's surface, giving an insight into its bulk properties.

The urea aqueous solution was placed in a quartz crucible of a few milliliters. For sample temperature control, the quartz crucible was placed in a thermomicrometric cooling/heating stage at atmospheric pressure. The instrument used was a thermomicrometric stage for geological applications (THMSG600, Linkam Scientific Instruments, Surrey, UK), a device offering a $0.1{ }^{\circ} \mathrm{C}$ resolution. Raman spectra were collected at temperatures between -30 and $10^{\circ} \mathrm{C}$ with a $0.5{ }^{\circ} \mathrm{C}$ temperature step and a $1 \mathrm{~s}$ per spectrum integration time. In order to ensure the sample's temperature stabilization, a pause of $30 \mathrm{~s}$ was set between each spectrum acquisition. The whole experimental setup is presented on Fig. 1.

Aqueous solutions with urea concentrations between 0 and $603 \mathrm{~kg} / \mathrm{m}^{3}$ were achieved by using the ASTM (American Society for Testing and Materials) D1193 type IV reagent water. A highly concentrated solution at $603 \mathrm{~kg} / \mathrm{m}^{3}$ was prepared by dilution of a $99.9 \%$ pure urea (supplied by Fisher Chemical) in the demineralized reagent water. The solutions with lower concentrations were obtained by dilution of this mother solution.

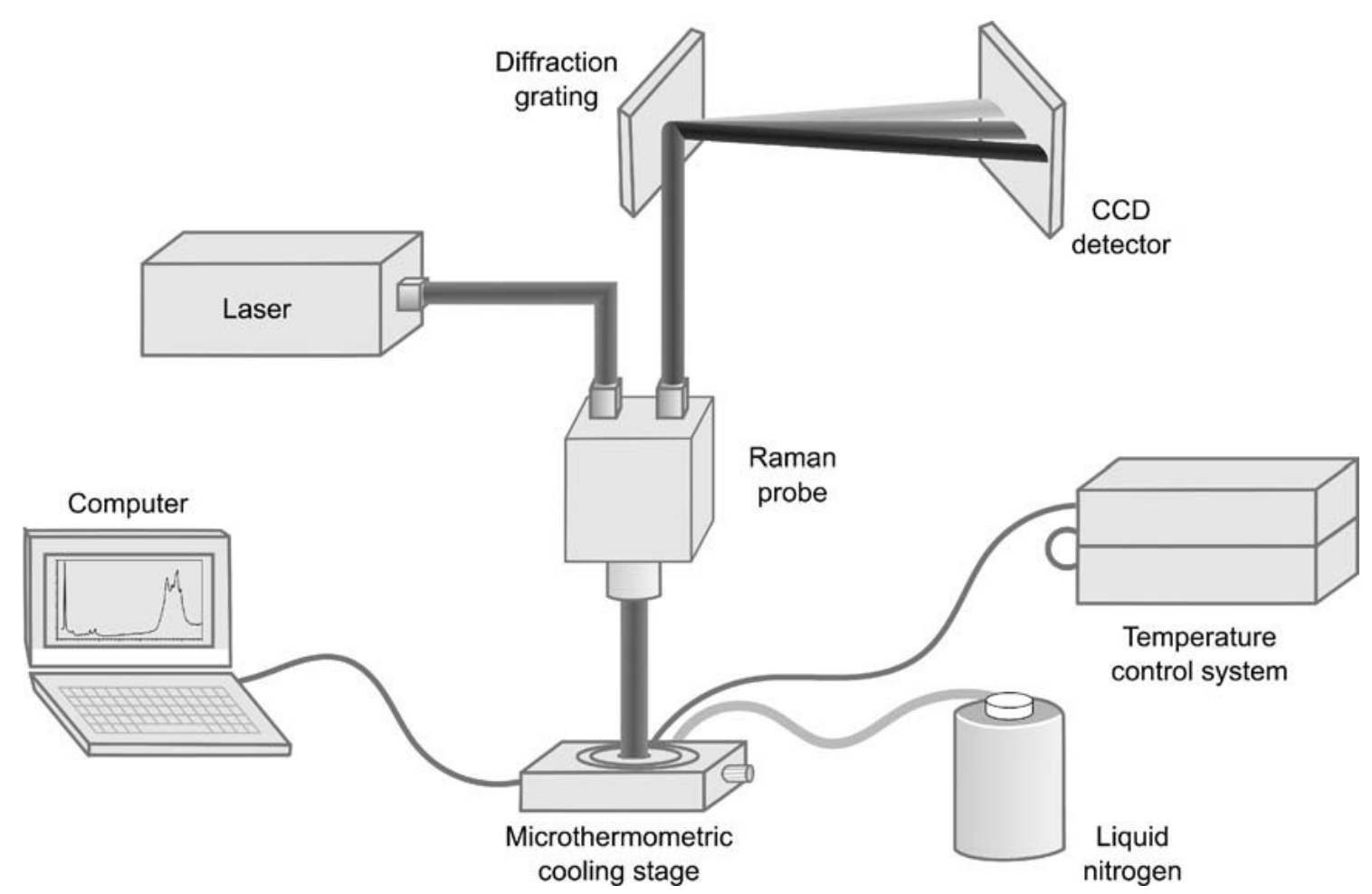

FIG. 1. Schematic representation of the used assembly. 


\section{PRELIMINARY CONSIDERATIONS}

Raman Spectra of Urea Aqueous Solutions. The urea concentration effect on the spectrum was observed by a comparison between spectra of urea solutions at different concentrations and one of water at room temperature. Normalized Raman spectra of urea aqueous solutions at different concentrations were acquired (Fig. 2a), and the water spectrum subtracted from them (Fig. 2b). The main peaks that are specific of the urea presence can thus be identified at 1006, 1155, 1460, 1590, and $1660 \mathrm{~cm}^{-1}$. Furthermore, the water's $\mathrm{O}-\mathrm{H}$ stretching vibrations ${ }^{13-15}$ above $3000 \mathrm{~cm}^{-1}$ are overlapped with some urea-characteristic peaks located at 3230, 3380, and $3480 \mathrm{~cm}^{-1}$. The attributions of all the peaks observed are presented in Fig. $2 b .{ }^{16-20}$ The main concentration influence is observed on the intensities of the peaks, with no significant peak shift.

The modification observed in the region above $3000 \mathrm{~cm}^{-1}$ induced by the concentration increase has two origins: the increase of the $\mathrm{NH}_{2}$ stretching vibrations, but also the modification of the $\mathrm{O}-\mathrm{H}$ stretching vibrations. Indeed, the presence of urea dissolved in water provokes the disruption of some hydrogen bonds, leading to an alteration of the hydrogen-bonding network. This is manifested by the modification of the symmetric/asymmetric stretching vibrations that are present in this spectral region.

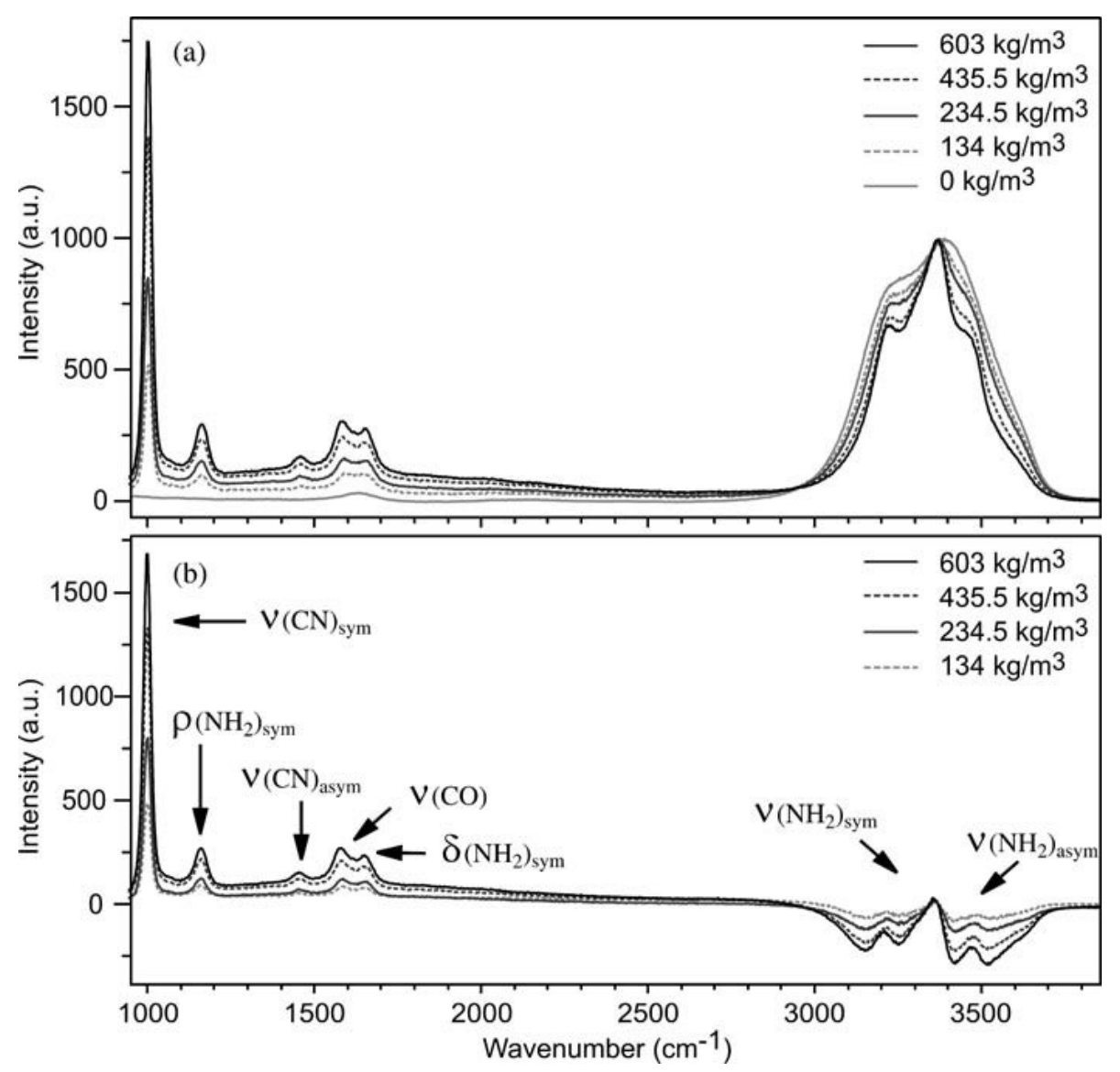

FIG. 2. Normalized Raman spectra of urea aqueous solutions at different concentrations, obtained at room temperature $\left(20^{\circ} \mathrm{C}\right.$ ) before (a) and after (b) subtraction of the water spectrum (laser power: $300 \mathrm{~mW}$; integration time: $20 \mathrm{~s}$ ).

Method for the Phase Transition Determination. The water spectrum presents a very intense signal in the 2900 to $3700 \mathrm{~cm}^{-1}$ range, which corresponds to the stretching of the $\mathrm{OH}$ bond of a water molecule. ${ }^{14,21,22}$

The phase transition of the liquid into solid water induces a collapse of the region above the 3300 $\mathrm{cm}^{-1}$ signature of the $\mathrm{OH}$ antisymmetric stretching vibrations and, by contrast, an intensity increase around $3200 \mathrm{~cm}^{-1}$, corresponding to the $\mathrm{OH}$ symmetric stretching vibrations ${ }^{23,24}$ (Fig. 3a). The water solidification, linked to an increased number of hydrogen bonds among water molecules, leads to an 
important increase of the peak at $3150 \mathrm{~cm}^{-1}$, which can be thus considered as characteristic of the ice presence.

This region is therefore a main key for the phase transition determination of water and aqueous solutions. ${ }^{25-27}$ The phase transition was then determined via the calculation of $S_{D}$, an area ratio of a band relevant of the liquid water (light gray band on Fig. 3a) to the one of the ice (dark gray band on Fig. 3a), as given in Eq. 1:

$$
S_{D}=\frac{\sum_{i=3350}^{3450}\left[\frac{I(i)+I(i-1)}{2} \times\{(i)-(i-1)\}\right]}{\sum_{i=3100}^{3200}\left[\frac{I(i)+I(i-1)}{2} \times\{(i)-(i-1)\}\right]}
$$

where (i) represent the wavenumber value and $I(i)$ the intensity at the corresponding (i).

The choices of the spectral bands used for the $S_{D}$ calculation are presented in Fig. 3a, and the resulting $S_{D}$ curve for water on Fig. 3b. The phase transition temperature is determined by the inflection point of this $S_{D}$ curve. For the case of water, an example presented in Fig. 3b, the freezing temperature obtained experimentally is $-1{ }^{\circ} \mathrm{C}$. Since the theoretical freezing point of water is $0{ }^{\circ} \mathrm{C}$, we can deduce the influence of the cooling stage on the freezing point obtained experimentally. Indeed, the slight depression in the cooling stage, as well as the size of its quartz crucible, influences the measurement and the sample response. For our experimental setup and procedure, the temperature shift induced by it is therefore $-1{ }^{\circ} \mathrm{C}$. As the same method was used in the study of the phase transitions of urea aqueous solutions, a $1^{\circ} \mathrm{C}$ correction was implemented.
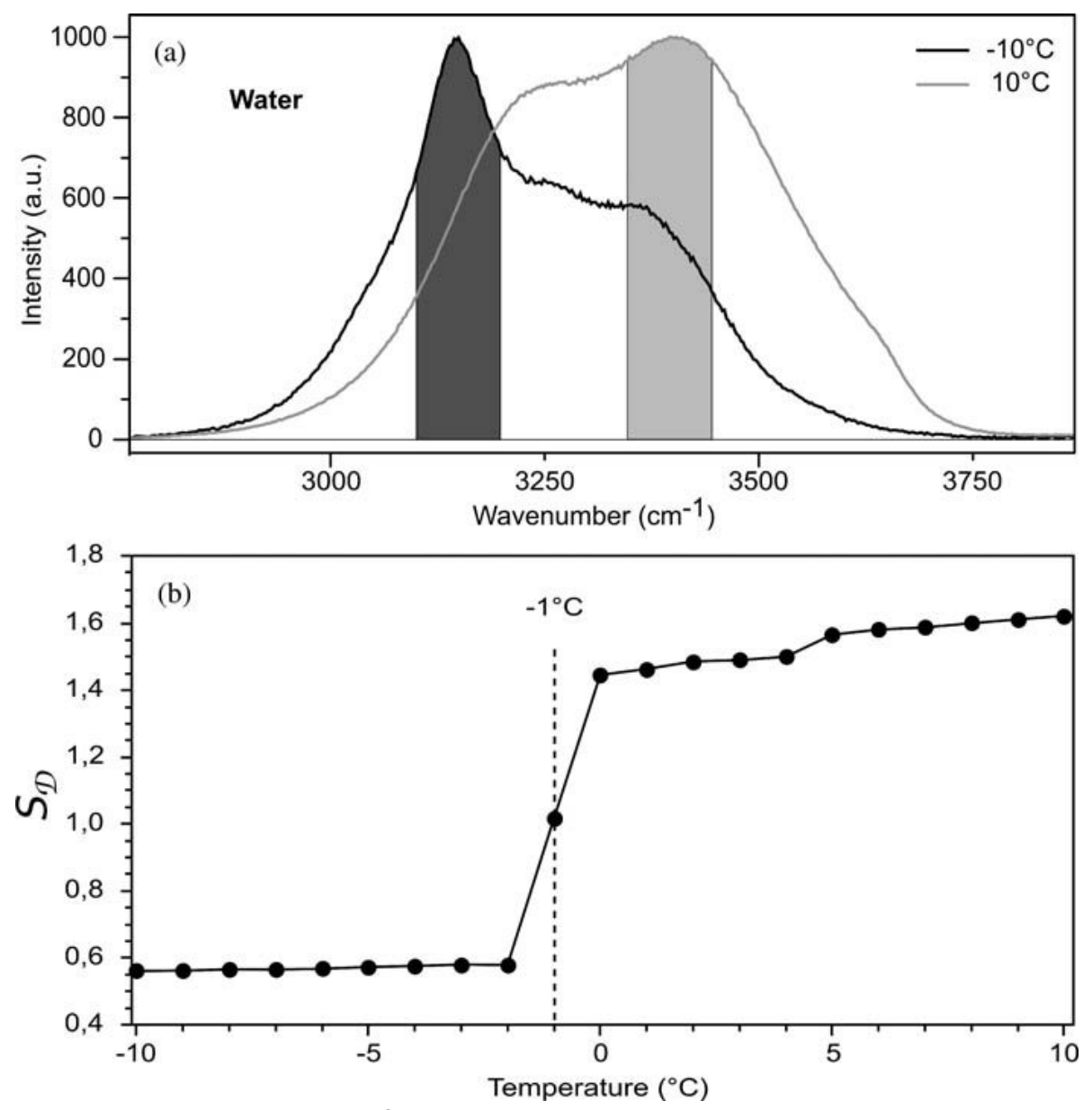

FIG. 3. Normalized Raman spectra of liquid water at $10^{\circ} \mathrm{C}$ and ice at $-10^{\circ} \mathrm{C}$ and the area bands used for the calculation of $S_{D}$ (a); evolution of $S_{D}$ according to the temperature from -10 to $10^{\circ} \mathrm{C}$

(b). 


\section{RESULTS AND DISCUSSION}

Phase Diagram Construction. The temperature range of interest in this paper is between 10 and $-30{ }^{\circ} \mathrm{C}$. In this temperature range, three phases can be identified, denoted liquid, solid, and mixture in this paper. Figure 4a presents these phases for an arbitrary chosen concentration of $134 \mathrm{~kg} / \mathrm{m}^{3}$ at arbitrary chosen temperatures $\left(-5,-14\right.$, and $\left.-30^{\circ} \mathrm{C}\right)$. Each spectrum has a different shape depending on the phase of the ura aqueous solution, and the effect of temperature within the same phase does not have a great effect on the structure. ${ }^{28}$ Similarly to water, the difference between the liquid and the mixture phases (at -5 and $-14^{\circ} \mathrm{C}$ ) can be observed in two ways. First, by the intensities: the peak related to $\mathrm{OH}$ asymmetric stretching vibrations decreases, and the ice peak at $3150 \mathrm{~cm}^{-1}$ increases. Second, these peaks undergo a wavenumber red-shift of about $100 \mathrm{~cm}^{-1}$ showing elongations of $\mathrm{NH}_{2}$ bonds during the liquid-mixture transition.

However, for urea aqueous solutions, a third phase can be observed at lower temperatures ( -30 ${ }^{\circ} \mathrm{C}$; Fig. 4a). This solid phase is characterized by the appearance of new peaks at 3337, 3355 and $3430 \mathrm{~cm}^{-1}$. If we draw a parallel between the urea-water binary system and the $\mathrm{NaCl}$-water one, this phase can then be compared to the hydrohalite one $\left(\mathrm{NaCl}_{2} 2 \mathrm{H}_{2} \mathrm{O}\right)$, usually observed at temperatures below the eutectic point. The solid phase thus corresponds to the eutectic mixture, the eutectic compound of urea being estimated to be $\mathrm{CO}\left(\mathrm{NH}_{2}\right)_{2} \cdot 8 \mathrm{H}_{2} \mathrm{O} \cdot{ }^{29}$

Using the method developed by Durickovic et al. ${ }^{26}$ for water, and the one of Claverie et al. ${ }^{27}$ for $\mathrm{NaCl}$ aqueous solutions, the two urea phase transitions of the $134 \mathrm{~kg} / \mathrm{m}^{3}$ solution were determined. As described in the preliminary considerations, areas corresponding to characteristic parts of the liquid water spectrum, and to ice, were considered (Eq. 1). The liquid-mixture and mixture-solid phase transition temperatures determined using the tangent method (Fig. 4b) were -17 and $-9{ }^{\circ} \mathrm{C}$.

The same spectra analysis method for the phase transition determination was applied on seven urea aqueous solutions. This enabled us to build the phase diagram of the urea-water system (Fig. 5) where the zones corresponding to the liquid, mixture, and solid phases can be observed. The eutectic point was determined, and it corresponded to a concentration of $335 \mathrm{~kg} / \mathrm{m}^{3}$. This would indicate that the corresponding eutectic compound is $\mathrm{CO}\left(\mathrm{NH}_{2}\right)_{2} \cdot 7 \mathrm{H}_{2} \mathrm{O}$, as the molar urea/water ratio at this concentration is $1 / 7$.

Information given by the Phase Diagram and the Eutectic Point. The knowledge of the eutectic concentration $C_{e}$ and temperature $T_{e}$ permits the identification of the characteristic zones of a corresponding phase diagram, giving an insight into the mixture's precise composition.

The mixture zone, corresponding to the zones contained between the "Liquidus" and "Solidus" lines, can thus be divided into two parts (Mixture a and Mixture b). Mixture a (corresponding to $T>$ $T_{e}$ and $C<C_{e}$ ) is composed of ice and urea solution (slush), whereas Mixture b ( $T>T_{e}$ and $C>$ $C_{e}$ ) is composed of urea and urea solution (slush). The eutectic concentration $C_{e}$ divides the solid zone, which can be found at $T<T_{e}$, in two as well. In this case, for $C<C_{e}$, the system is composed of ice and solid eutectic, and for $C>C_{e}$, the system becomes composed of urea and solid eutectic. 

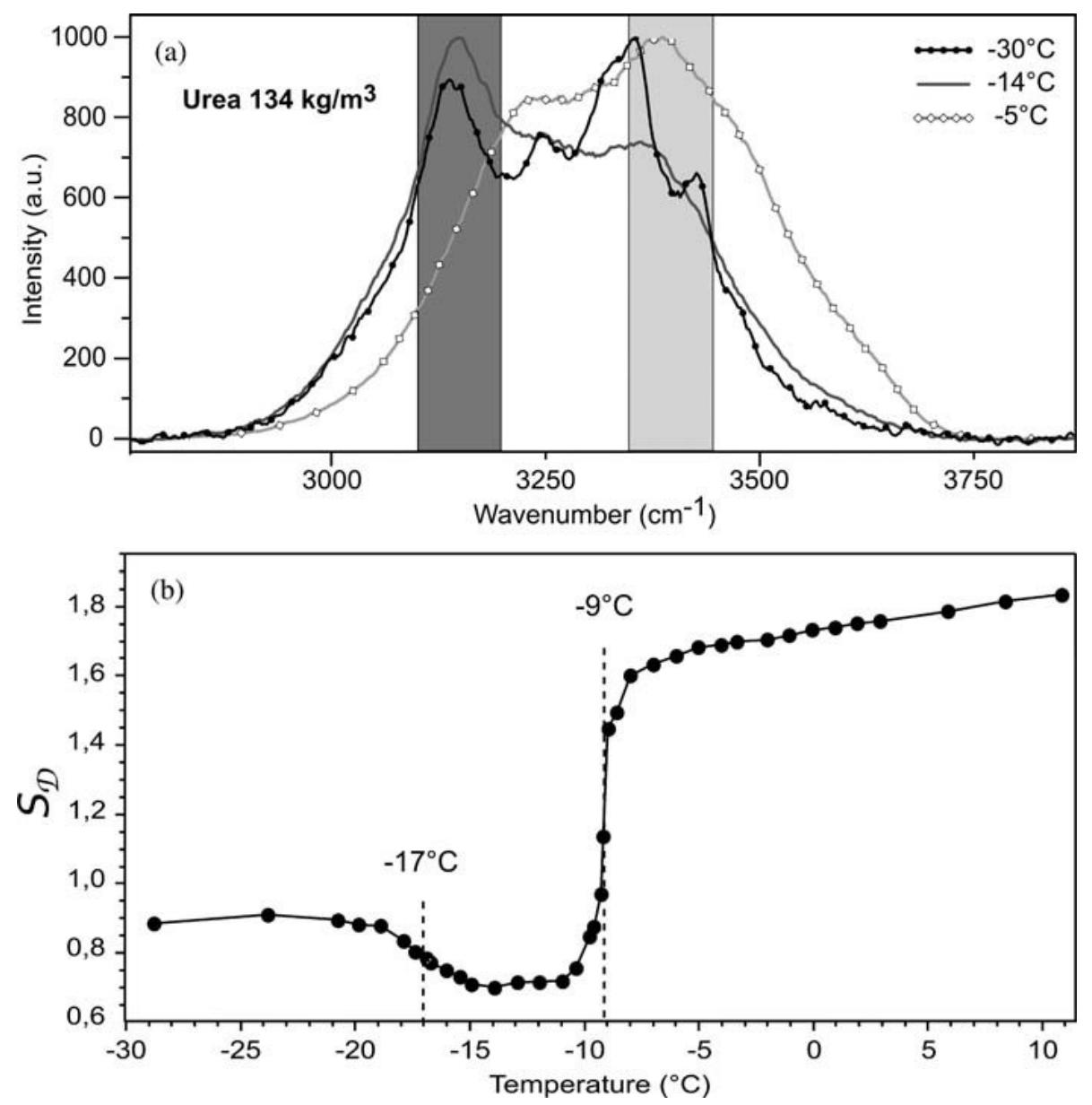

FIG. 4. Normalized Raman spectra of the different phases of the urea solution at $134 \mathrm{~kg} / \mathrm{m}^{3}$ (a); evolution of $S_{D}$ according to the temperature from -30 to $10^{\circ} \mathrm{C}$ for a urea solution at $134 \mathrm{~kg} / \mathrm{m}^{3}(\mathbf{b})$.

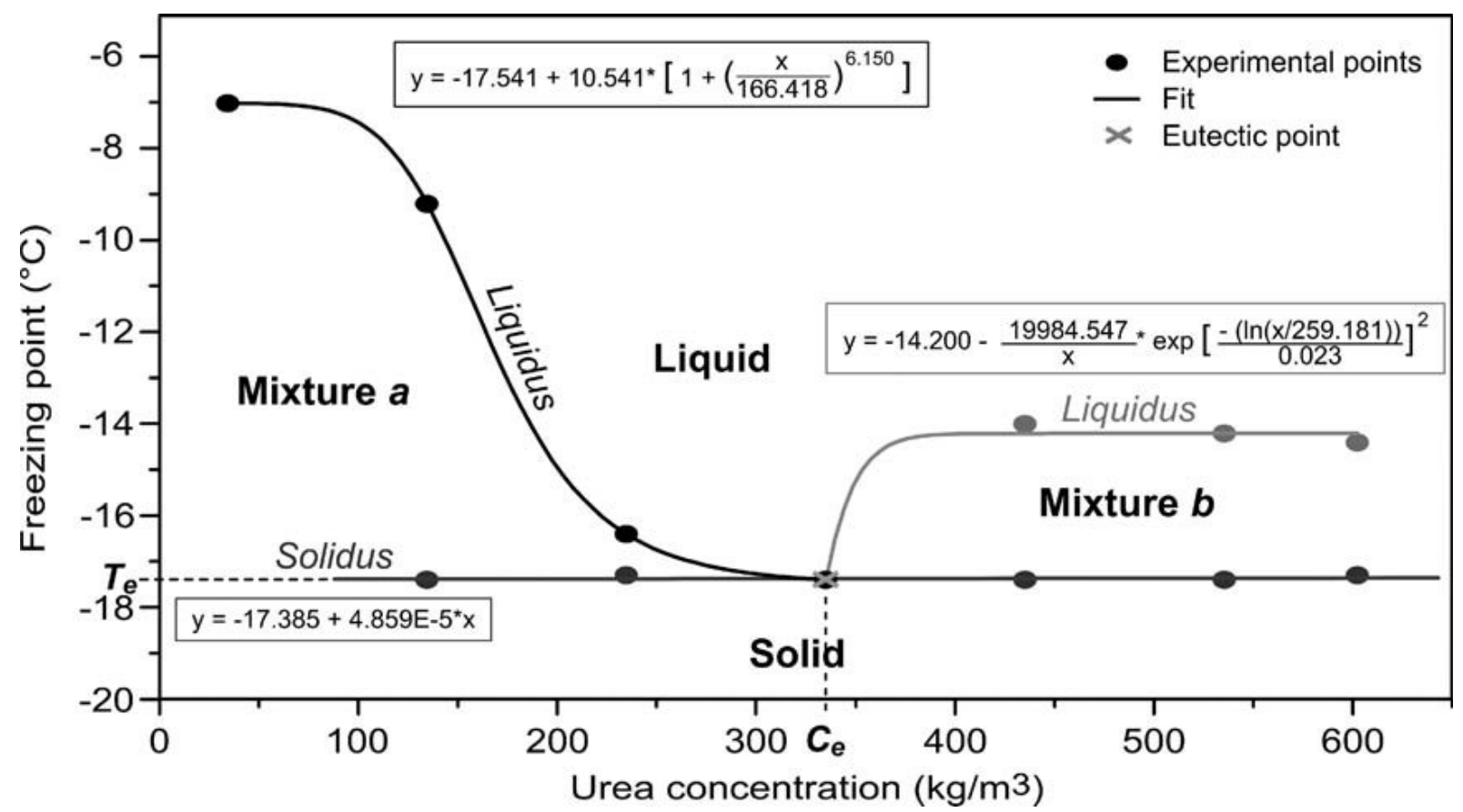

FIG. 5. Urea-water binary liquid-solid phase diagram obtained experimentally by the use of $S_{D}$. 


\section{CONCLUSION}

Urea aqueous solutions were investigated in a wide range of concentrations and temperatures by means of Raman spectroscopy in order to build its phase diagram.

Raman spectra were recorded at temperatures ranging from 10 to $-30^{\circ} \mathrm{C}$, for urea concentrations up to $600 \mathrm{~kg} / \mathrm{m}^{3}$. Raman spectroscopy proved to be an appropriate technique for the characterization of urea aqueous solutions by the analysis of the material molecule's bond vibrations, as well as for the determination of their phases. The phase transitions in aqueous solutions were identified using a simple method based on areas of two large bands in the high wavenumber range of the spectra, which allowed us to build the urea-water phase diagram at low temperatures. A eutectic point was identified, along with a specific phase below the temperature of this eutectic point. Some additional investigations will be undertaken to confirm the nature and the molar urea/water ratio of the eutectic mixture at temperatures below the eutectic point by conventional techniques, such as X-ray diffraction.

Phase transitions are difficult to reach and to identify since they highly depend on the conditions at which they occur. It could specifically be the case at low temperatures because of the coexistence of several phases, along with local thermal gradients within the material considered. Raman spectroscopy appeared to be the proper tool to overcome these usual difficulties. It could then be able to analyze not only bond vibrations, whatever the phases are, but also the singularities that a phase transition could induce.

\section{REFERENCES}

1. F. Wohler. "Ueber kuünstliche Bildung des Harnstoffs". Ann. Phys. Chem. 1828. 88(2): 253-256.

2. J.B. Mazaud. "Urée”. Production des gaz de synthèse. Paris, France: Techniques de l'Ingénieur. 2001. J6660-1-J6660-6.

3. M. Eichelbaum, A.B. Siemer, R.J. Farrauto, M.J. Castaldi. "The Impact of Urea on the Performance of Metal Exchanged Zeolites for the Selective Catalytic Reduction of NOx. Part I. Pyrolysis and Hydrolysis of Urea over Zeolite Catalysts”. Appl. Catal., B. 2010. 97(1-2): 90-97.

4. G. Plassat. "Premiers résultats de système DeNox SCR par injection d’urée sur BUS Euro 5”. [Technical Report]. Agence de l’Environnement et de la Maîtrise de l’Énergie. 2005.

5. C. Zamfirescu, I. Dincer. "Utilization of Hydrogen Produced from Urea on Board to Improve Performance of Vehicles”. Int. J. Hydrogen Energy 2011. 36(17): 11425-11432.

6. M. Koebel, M. Elsener, M. Kleemann. "Urea-SCR: A Promising Technique to Reduce NOx Emissions from Automotive Diesel Engines”. Catal. Today. 2000. 59(3-4): 335-345.

7. R. Moos, R. Muller, C. Plog, A. Knezevic, H. Leye, E. Irion, T. Braun, K.J. Marquardt, K. Binder. "Selective Ammonia Exhaust Gas Sensor for Automotive Applications". Sens. Actuators, B. 2002. 83(1-3): 181-189.

8. S.A. Ketcham, L.D. Minsk, R.R. Blackburn, E.J. Fleege. "Manual of Practice for an Effective Anti-icing Program: A Guide for Highway Winter Maintenance Personnel”. [Technical Report FHWA-RD-95202]. Washington, DC: U.S. Department of Transportation, Federal Highway Administration, 1996.

9. R.R. Blackburn, K.M. Auer, D.E. Amsler, S.E. Boselly, A.D. McElroy." Snow and Ice Control: Guidelines for Materials and Methods”. [Technical Report NCHRP 526]. Washington, DC: National Cooperative Highway Research Program, Transportation Research Board of the National Academies, 2004.

10. K.D. Ferguson. “Minimizing the Environmental Impact of Urea De-icer from Airport Runways”. [M.S. Dissertation]. Vancouver, Canada: University of British Columbia. 1977.

11. D.A. Turnbull, J.R. Bevan. "The Impact of Airport De-Icing on a River: The Case of the Ouseburn, Newcastle upon Tyne”. Environ. Pollut. 1995. 88(3): 321-332.

12. M.D. Fayer. "Raman and IR Spectroscopy of Liquids". In: M. D. Fayer, editor. Ultrafast Infrared and Raman Spectroscopy. New York: Taylor and Francis-Routledge, 2001. Pp. 1-80.

13. B.M. Auer, J.L. Skinner. "IR and Raman Spectra of Liquid Water: Theory and Interpretation”. J. Chem. Phys. 2008. 128: 224511-1-224511-12.

14. Q. Sun. “The Raman OH Stretching Bands of Liquid Water”. Vib. Spectrosc. 2009. 51(2): 213-217.

15. G.E. Walrafen, L.A. Blatz. “Weak Raman Bands from Water”. J. Chem. Phys. 1973. 59(5): 2646-2650. 
16. R. Keuleers, H.O. Desseys, B. Rousseau, C. Van Alsenoy. "Vibrational Analysis of Urea”. J. Phys. Chem. 1999. 103(24): 4621-4630.

17. J. Grdadolnik, Y. Marechal. "Urea and Urea-Water Solutions-An Infrared Study”. J. Mol. Struct. 2002. 615(1-3): 177-189.

18. Y.M. Jung. "Two-Dimensional Correlation Spectroscopy in Analyzing the Concentration-Dependent IR Spectra of Urea Aqueous Solution”. Bull. Korean Chem. Soc. 2003. 24(9): 1243-1244.

19. Y.M. Jung, B. Czarnik-Matusewicz, S.B. Kim. "Characterization of Concentration-Dependent Infrared Spectral Variations of Urea Aqueous Solutions by Principal Component Analysis and Two-Dimensional Correlation Spectroscopy”. J. Phys. Chem. B. 2004. 108: 13008-13014.

20. A. Idrissi. "Molecular Structure and Dynamics of Liquids: Aqueous Urea Solutions”. Spectrochim. Acta A. 2005. 61(1-2): 1-17.

21. A.M. Pereira Neto, O. Sala. "The Effect of Temperature and LiClO 4 in the Water Structure: A Raman Spectroscopy Study”. Braz. J. Phys. 2004. 34(1): 137-142.

22. J.M. Schicks, J. Erzinger, M.A. Ziemann. "Raman Spectra of Gas Hydrates-Differences and Analogies to Ice $1 \mathrm{~h}$ and (Gas Saturated) Water”. Spectrochim. Acta A. 2005. 61(10): 2399-2403.

23. I. Durickovic, M. Marchetti, R. Claverie, P. Bourson, J.-M. Chassot, M.D. Fontana. "Experimental Study of $\mathrm{NaCl}$ Aqueous Solutions by Raman Spectroscopy: Towards a New Optical Sensor”. Appl. Spectrosc. 2010. 64(8): 853-857.

24. P. Shriver, W. Atkins. Inorganic Chemistry. Oxford, UK: Oxford University Press, 2001. 4th ed.

25. I. Durickovic, M. Marchetti, R. Claverie-Rospide, J. Livet, P. Bourson, M. Fontana, J.-M. Chassot. "Process for the Determination of the Solid/Liquid Phase". Patent 0857090. Filed 2008. Issued 2010.

26. I. Durickovic, R. Claverie, P. Bourson, M. Marchetti, J.-M. Chassot, M.D. Chassot. "Water-Ice Phase Transition Probed by Raman Spectroscopy”. J. Raman Spectrosc. 2011. 42: 1408-1412.

27. R. Claverie, M.D. Fontana, I. Durickovic, P. Bourson, M. Marchetti, J.-M. Chassot. "Optical Sensor for Characterizing the Phase Transition in Salted Solutions”. Sensors. 2010. 10: 3815-3823.

28. A. Idrissi, E. Cinar, S. Longelin, P. Damay. "The Effect of Temperature on Urea-Urea Interactions in Water: A Molecular Dynamics Simulation”. J. Mol. Liq. 2004. 110(1-3): 201-208.

29. M. Egal. "Structure and Properties of Cellulose/NaOH Aqueous Solutions, Gels and Regenerated Objects”. [Ph.D. Thesis]. Paris, France: Ecole des Mines de Paris, 2006. 